\title{
Hydrogen sulfide protects against the development of experimental cerebral malaria in a $\mathrm{C} 57 \mathrm{BL} / 6$ mouse model
}

\author{
PING JIANG $^{1}$, ZHISHEN XU ${ }^{1}$, BAIQUAN XIAO ${ }^{1,2}$, ZHONG HAN $^{1,2}$, \\ JIEHONG HUANG ${ }^{1}$, JIANBANG XU ${ }^{1}$, ZHAORONG LUN ${ }^{1}$ and WENLIANG ZHOU ${ }^{1}$
}

\author{
${ }^{1}$ School of Life Sciences, Sun Yat-Sen University, Guangzhou, Guangdong 510275; ${ }^{2}$ Center of Pharmacological Research, \\ Guangdong Lewwin Pharmaceutical Research Institute Co., Ltd., Guangzhou, Guangdong 510990, P.R. China
}

Received February 15, 2016; Accepted February 20, 2017

DOI: $10.3892 / \mathrm{mmr} .2017 .6854$

\begin{abstract}
Hydrogen sulfide $\left(\mathrm{H}_{2} \mathrm{~S}\right)$ has anti-inflammatory and neuroprotective properties, particularly during pathological processes. Experimental cerebral malaria (ECM), which is caused by vascular leakage into the brain, is characterized by inflammation, neurological deficits and cerebral hemorrhage. The present study investigated the correlation between ECM genesis and the levels of $\mathrm{H}_{2} \mathrm{~S}$. The results indicated that the levels of $\mathrm{H}_{2} \mathrm{~S}$ derived from the brain decreased over time following ECM infection, and that the low $\mathrm{H}_{2} \mathrm{~S}$ bioavailability was partially caused by decreased expression of the $\mathrm{H}_{2} \mathrm{~S}$ generating enzyme, cystathionine- $\beta$-synthase. Administration of NaHS (an exogenous donor of $\mathrm{H}_{2} \mathrm{~S}$ ) provided protection against ECM. NaHS inhibited the destruction of the blood brain barrier and the secretion of proinflammatory biomarkers, including interluekin-18, matrix metalloproteinase-9 and serum cluster of differentiation 40 into the brain during ECM. In conclusion, these results suggested that low levels of $\mathrm{H}_{2} \mathrm{~S}$ in brain contributed to the progression of ECM, and that $\mathrm{H}_{2} \mathrm{~S}$ donor administration may represent a potential protective therapy against ECM.
\end{abstract}

\section{Introduction}

Cerebral malaria is a devastating infectious disease, and its symptoms at an advanced stage include coma, neurological dysfunction, inflammation, severe anemia and acidosis. Mortality in patients with cerebral malaria primarily occurs due to the lack of or delay in administration of suitable treatments. Even when proper intervention is received, the mortality rate of cerebral malaria is $15-20 \%$ (1). Furthermore,

Correspondence to: Professor Zhaorong Lun or Professor Wenliang Zhou, School of Life Sciences, Sun Yat-Sen University, 135 West Xingang Road, Guangzhou, Guangdong 510275, P.R. China

E-mail:1sslzr@mail.sysu.edu.cn

E-mail: 1sszwl@mail.sysu.edu.cn

Key words: hydrogen sulfide, experiment cerebral malaria, Plasmodium berghei ANKA, blood brain barrier, inflammation out of the children who survive cerebral malaria, $15 \%$ exhibit permanent neurological impairment $(1,2)$.

In last few decades, multiple reports have revealed that hydrogen sulfide $\left(\mathrm{H}_{2} \mathrm{~S}\right)$ is a bioactive molecule, exerting multiple functions in physiological and pathological processes. One of the important physiological functions of $\mathrm{H}_{2} \mathrm{~S}$ is that it serves as an endogenous anti-inflammatory agent (3-5). Several $\mathrm{H}_{2} \mathrm{~S}$-releasing drugs are currently being developed for the treatment of many types of inflammatory diseases $(6,7)$. For instance, in a rat model of carrageenan-induced hind paw edema, it was demonstrated that the $\mathrm{H}_{2} \mathrm{~S}$ donor, sodium hydrosulfide, provided protection against inflammation and edema formation, potentially due to its strong inhibitory effects on leukocyte adherence to the vascular endothelium, resulting in a significant decrease of paw volume (8).

Furthermore, $\mathrm{H}_{2} \mathrm{~S}$ has been demonstrated to be an important neuroprotectant by its ability to enhance NMDA receptor-mediated responses and induce hippocampal long-term potentiation $(9,10)$. In addition, previous reports demonstrated that $\mathrm{H}_{2} \mathrm{~S}$ serves as a neuronal defense against hypochlorous acid- or lipopolysaccharide-induced neuroinflammation $(11,12)$.

Despite its involvement in the regulation of inflammation and neuro-protection, the involvement of $\mathrm{H}_{2} \mathrm{~S}$ in cerebral malaria pathogenesis remains poorly understood. The primary aim of the present study was to investigate the effects of $\mathrm{H}_{2} \mathrm{~S}$ in the development of cerebral malaria.

\section{Materials and methods}

Plasmodium berghei ANKA (PbA) infection. C57BL/6 mice (6-8 weeks; 21-25 g; male, $\mathrm{n}=80$; and female, $\mathrm{n}=80$ ) were purchased from the Guangdong Medical Laboratorial Animals Center (Guangzhou, China). All protocols were approved and followed the guidelines of the Animal Use Committee of Sun Yat-Sen University (Guangzhou, China). Animals were maintained at room temperature $\left(24 \pm 0.5^{\circ} \mathrm{C}\right)$ in a 12 -h light/dark cycle and were allowed ad libitum access to food and water. $P b A$ was thawed and inoculated in one C57BL/6 mouse. Parasitaemia of the infected mouse was detected by Giemsa-stain of a blood smear. Briefly, a drop of blood from tails was placed on a glass slide and another glass slide was used to form a layer of film on the glass. Giemsa A solution 
was added to blood film and incubated for $10 \mathrm{~min}$ at room temperature, Giemsa A solution was washed off with water and Giemsa B solution was added and incubated for $10 \mathrm{~min}$, followed by a further wash with water. The number of infected red blood cells (iRBCs) out of a total of 1,000 RBCs was counted under an oil immersion lens (x100) of a light microscope. Giemsa-staining was performed on the infected mouse every day following infection, on three individual glass slides each time. When the infection rate reached $50 \%$, the $\mathrm{iRBCs}$ from this infected mouse were subsequently used to infect all other mice (13). Parasitaemia of all other mice was detected by Giemsa-staining on the day before infection, and at 2, 3 and 6 days after infection.

Cumulative survival. Each mouse was infected with $1 \times 10^{6}$ iRBCs. A total of 40 infected mice were randomly divided into saline, NaHS, L-cysteine and aminooxyacetic acid (AOAA) groups ( $\mathrm{n}=10$ mouse per group). Saline, NaHS (an exogenous donor of $\mathrm{H}_{2} \mathrm{~S} ; 1 \mathrm{mg} / \mathrm{kg}$ ), L-cysteine (an endogenous donor of $\mathrm{H}_{2} \mathrm{~S} ; 0.3 \mathrm{mg} / \mathrm{kg}$ ), or AOAA [cystathionine- $\beta$-synthase (CBS) inhibitor; $10 \mathrm{mg} / \mathrm{kg}$ ] was injected intraperitoneally into mice three times a day. The survival rate was confirmed by quantitative assessment using a rapid murine coma and behavior scale of cerebral malaria (14).

Extravasation of Evans blue. A total of 50 mice were randomly divided into two groups: Uninfected $(n=10)$ and infected $(n=40)$. Following infection with $1 \times 10^{6}$ iRBCs, the 40 mice were randomized into four groups: Infection group treated with saline for 2 days (D2+saline; $n=10)$, infection group treated with NaHS for 2 days (D2+NaHS; n=10), infection group treated with saline for 6 days (D6+saline; $n=10$ ), and infection group treated with NaHS for 6 days (D6+NaHS; $\mathrm{n}=10$ ). Mice were subsequently anesthetized by a subcutaneous injection of $40 \mathrm{mg} / \mathrm{kg}$ sodium pentobarbital (Guangzhou Qiyun Biotechnology Co., Ltd., Guangzhou, China). The right caudal vein was cannulated with polyethylene tubing and $200 \mathrm{nnu}$ Evans blue (2\% in saline) was administered via the catheter. This procedure was followed by an injection of $200 \mu 10.9 \%$ saline. After $30 \mathrm{~min}$, all mice were killed by dislocating cervical vertebra. The hair and skin of mice heads were removed by surgical scissors, the top of skull was split along the gap with scissors and the brain was gently removed from the skull. Extracted brains were placed in $1 \mathrm{ml} \mathrm{N}, \mathrm{N}$-dimethylformamide (Sigma-Aldrich; Merck Millipore, Darmstadt, Germany) for $48 \mathrm{~h}$ to extract the Evans blue dye (15), and the absorbance of the Evans blue dye solution was measured at a wavelength of $630 \mathrm{~nm}$ using a spectrophotometer.

Acquisition of plasma, brain, liver and spleen. A total of 70 mice were randomly divided into the uninfected group, infection group treated with saline for 2 days (D2+saline), infection group treated with NaHS for 2 days (D2+NaHS), infection group treated with saline for 3 days (D3+saline), infection group treated with NaHS for 3 days (D3+NaHS), infection group treated with saline for 6 days (D6+saline), and infection group treated with NaHS for 6 days (D6+NaHS), n=10 per group. Subsequently, all mice were killed by dislocating cervical vertebra. Following administration, the spleen, brain and liver were carefully excised and weighed. The brain tissues were incised into four parts. One was placed in pH-balanced $10 \%$ formalin, embedded by paraffin, sectioned $(8 \mu \mathrm{m})$ and examined by hematoxylin and eosin (H\&E) staining, two were used for total RNA and protein measurement, respectively, and the rest were ground into homogenate for measurement of $\mathrm{H}_{2} \mathrm{~S}$ by ELISA (cat. no. 10355371; Shanghai Institute of Biotechnology Co., Ltd., Shanghai, China). The plasma was drawn out for measurement of interleukin-18 (IL-18; cat. no. 7625), matrix metalloproteinase-9 (MMP-9; cat. no. MMPT90) and serum cluster of differentiation 40 (sCD40; cat. no. MCCD40) by ELISA (R\&D Systems, Inc., Minneapolis, MN, USA), following the manufacturer's protocol.

Reverse transcription-polymerase chain reaction (RT-PCR). Total RNA was isolated from the brain tissue using TRIzol ${ }^{\circledR}$ (Invitrogen; Thermo Fisher Scientific, Inc., Waltham, MA, USA). RT-PCR was performed using the Prime Script ${ }^{\circledR}$ RT-PCR kit (Takara Biotechnology Co., Ltd., Dalian, China) following the manufacturer's protocol. The PCR conditions involved initialization at $94^{\circ} \mathrm{C}$ for $3 \mathrm{~min}$, followed by 40 cycles of denaturation at $94^{\circ} \mathrm{C}$ for $30 \mathrm{sec}$, annealing at $60^{\circ} \mathrm{C}$ for $30 \mathrm{sec}$ and polymerization at $72^{\circ} \mathrm{C}$ for $30 \mathrm{sec}$, final elongation was performed at $72^{\circ} \mathrm{C}$ for $10 \mathrm{~min}$. The primer sequences for CBS were as follows: Forward, 5'-CGTGAGCAGACCCAGACA T-3' and reverse, 5'-GCTACTCGGGCATAGAGGATT-3'.

Western blot analysis. Proteins were extracted from brain tissue, briefly, brain tissue was triturated in a tissue mortar with RIPA lysis buffer (Beyotime Institute of Biotechnology, Haimen, China) at $4^{\circ} \mathrm{C}$ for $10 \mathrm{~min}$, the brain lysate solution was centrifuged at $15,000 \mathrm{x} \mathrm{g}$ and $4^{\circ} \mathrm{C}$ for $10 \mathrm{~min}$. Following centrifugation, the supernatant was collected. Protein $(80 \mu \mathrm{g})$ was loaded onto each lane, separated by $10 \%$ SDS-PAGE and subsequently transferred to a polyvinylidene difluoride membrane. The membrane was blocked in 5\% nonfat milk powder for $30 \mathrm{~min}$ and subsequently probed with rabbit polyclonal CBS (1:1,000; cat. no. H00000875-D01P; Abnova, Taipei, Taiwan) and rabbit monoclonal GAPDH (1:1,000; cat. no. 2118S; Cell Signaling Technology, Inc., Danvers, MA, USA) primary antibodies for $2 \mathrm{~h}$ at room temperature, followed by incubation with horseradish peroxidase-conjugated goat anti-rabbit IgG secondary antibody (1:20,000; cat. no. E030120; EarthOx Life Sciences, Millbrae, CA, USA) for $1 \mathrm{~h}$ at room temperature. Membranes were developed with an Enhanced Chemiluminescence reagent (LumiGold; SignaGen Laboratories, Rockville, MD, USA) and a Tanon $5200 \mathrm{Gel}$ Imaging System.

Statistical analysis. Data are presented as the mean \pm standard error of the mean. Database construction and statistical analyses were performed using Origin 8.5 software (OriginLab Corporation, Northampton, MD, USA). Data were analyzed by analysis of variance followed by Bonferonni's post hoc test, or two-tailed Student's t-test. $\mathrm{P}<0.05$ was considered to indicate a statistically significant difference.

\section{Results}

ECM model validation. Following infection with $P b A$, the amount of parasitized red blood cells was detected by Giemsa 

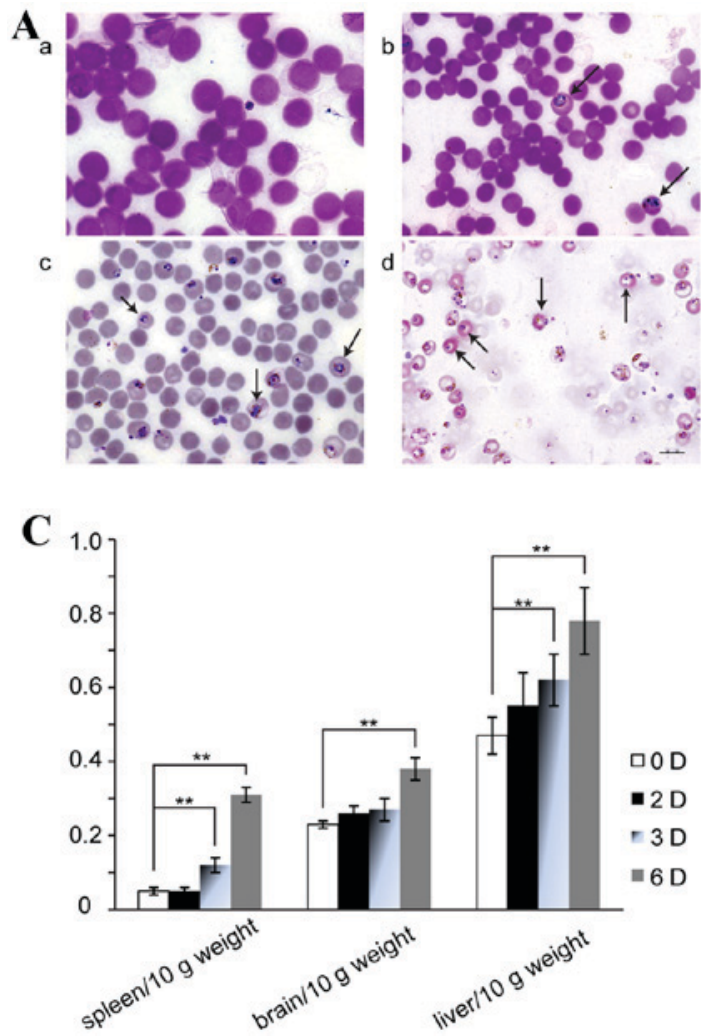

B
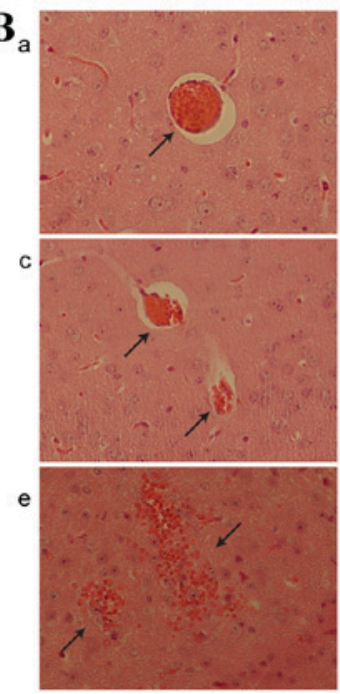
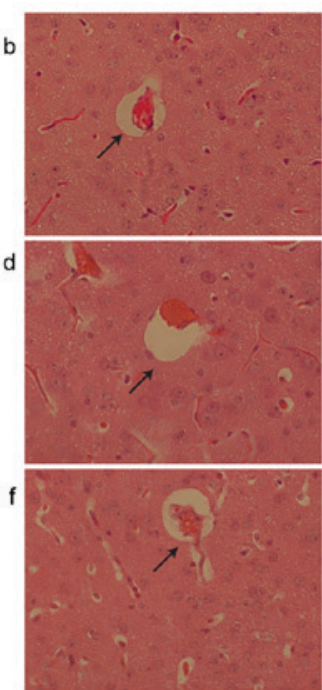

Figure 1. Validation of the experimental cerebral malaria model. (A) Results of Giemsa staining. Parasitized red blood cells are indicated by black arrows. The number of parasitized red blood cells increased with time. a, uninfected group; b, D2+saline group; c, D3+saline group; d, D6+saline group. (Scale bar=10 $\mu$ m). (B) Cerebral micro-vessels as viewed by hematoxylin and eosin staining. a, D2+saline; b, infected group treated with NaHS (1 mg/kg) for 2 days; c, D3+saline; $\mathrm{d}$, infected group treated with NaHS (1 mg/kg) for 3 days; e, D6+saline; f, infected group treated with NaHS (1 mg/kg) for 6 days. Black arrows indicate hemorrhages or blood vessels. Magnification, $x 40$. (C) Alterations in spleen, brain and liver indexes. Data are presented as the mean \pm standard error of the mean, $\mathrm{n}=10.0 \mathrm{D}$, uninfected group; 2 D, D2+saline; 3D, D3+saline; 6 D, D6+saline. D2+saline, infected group treated with saline for 2 days; D3+saline, infected group treated with saline for 3 days; D6+saline, infected group treated with saline for 6 days. ${ }^{* *} \mathrm{P}<0.01$.

staining of a blood smear (Fig. 1A). Hemorrhage into the brain on day 6 of ECM in saline-treated mice was additionally demonstrated by H\&E-staining (Fig. 1B). Similarly, the hemorrhage was visibly reduced in the $\mathrm{H}_{2} \mathrm{~S}$ donor administration group (Fig. 1B), while no apparent hemorrhage was observed on day 2 or 3 following infection with or without NaHS treatment (Fig. 1B). In contrast, significant hemorrhaging in the brain was observed on day 6 of ECM (Fig. 1B). In addition, the indexes of spleen, brain and liver/10 $\mathrm{g}$ weight increased gradually in a time-dependent manner (Fig. 1C).

CBS levels of ECM. Alterations in CBS levels during ECM were assessed using RT-PCR and western blotting. The RT-PCR results revealed that $\mathrm{CBS}$ mRNA levels decreased gradually with saline treatment time (Fig. 2A). Compared with day 0 , CBS mRNA expression levels visibly decreased following saline treatment for 3 and 6 days (Fig. 2A). Consistently, CBS protein expression levels demonstrated similar reduction patterns (Fig. 2B).

$\mathrm{H}_{2} \mathrm{~S}$ levels of ECM. The concentration of $\mathrm{H}_{2} \mathrm{~S}$ in the brain was measured by ELISA. The levels of $\mathrm{H}_{2} \mathrm{~S}$ in the brain decreased gradually with saline treatment time, and were significantly reduced on day 3 (28.40 \pm 0.14 vs. $31.00 \pm 0.54$; $\mathrm{P}<0.05$; Fig. $2 \mathrm{C})$ and day 6 of saline treatment $(25.35 \pm 0.46$ vs. $31.00 \pm 0.54$, $\mathrm{P}<0.05$; Fig. 2C) compared with day 0 .
Survival of ECM. Following treatment with NaHS, L-cysteine or AOAA, the survival of mice with ECM was evaluated by quantitative assessment of coma and behavior scales of ECM. The results revealed that only $2 / 10$ saline-treated mice survived 8 days following infection. Mice treated with NaHS survived significantly longer than saline-treated mice; 8/10 NaHS-treated mice were alive at day 8 following infection. However, the mice treated with L-cys demonstrated no significant difference from mice treated with saline, and all mice treated with AOAA, a CBS inhibitor, died by day 7 following infection. The difference of survival rate between the saline and NaHS-treated groups at days 8 and 9 was significant $(\mathrm{P}<0.05$; Fig. 3$)$.

Integrity of the blood brain barrier $(B B B)$ during ECM. The integrity of the BBB was assessed by Evans blue extravasation, H\&E staining and measurement of MMP-9. On day 2 of ECM there was no significant increase in Evans blue extravasation in the ECM brain (Fig. 4). In contrast, on day 6 of ECM, a significant increase in Evans blue in the brains of saline-treated mice was observed compared with uninfected mice (Fig. 4). Furthermore, administration of $\mathrm{H}_{2} \mathrm{~S}$ donor significantly decreased Evans blue extravasation into the brain compared with saline-injected mice ( $\mathrm{n}=10$ per group, $\mathrm{P}<0.05$; Fig. 4).

MMP-9 protein expression levels in the infection group treated with saline $(41.52 \pm 2.99 \mathrm{ng} / \mathrm{ml})$ was $\sim 3$ times increased compared with the uninfected group $(12.32 \pm 1.30 \mathrm{ng} / \mathrm{ml})$ as 
A

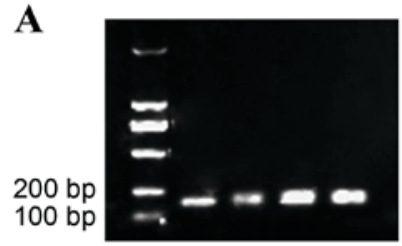

B
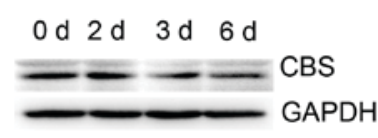

$M 6 d 3 d 2 d 0 d$

\section{C}

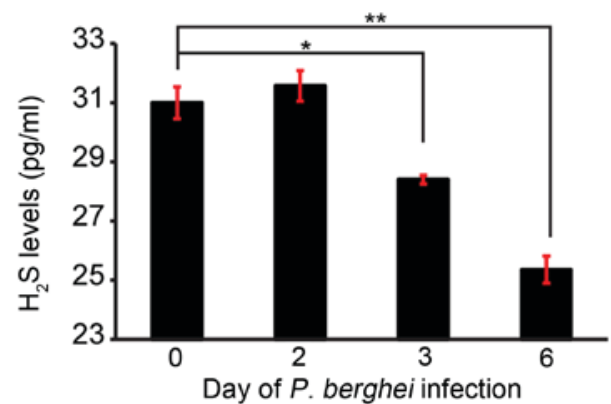

Figure 2. $\mathrm{H}_{2} \mathrm{~S}$ levels in the ECM-infected brain. (A) Reverse transcription polymerase chain reaction results demonstrated that CBS mRNA levels gradually decreased at the transcriptional level in a time-dependent manner (B) Representative western blot image of CBS protein expression levels GAPDH served as an internal control. (C) The levels of $\mathrm{H}_{2} \mathrm{~S}$ derived from the brain were measured by ELISA. Data are presented as the mean \pm standard error of the mean, $\mathrm{n}=10 .{ }^{*} \mathrm{P}<0.05$ and ${ }^{* *} \mathrm{P}<0.01$ vs. 0 D. $0 \mathrm{D}$, uninfected group $2 \mathrm{D}$, infection group treated with saline for 2 days; $3 \mathrm{D}$, infection group treated with saline for 3 days; $6 \mathrm{D}$, infection group treated with saline for 6 days. ECM, experimental cerebral malaria; CBS, cystathionine- $\beta$-synthase.

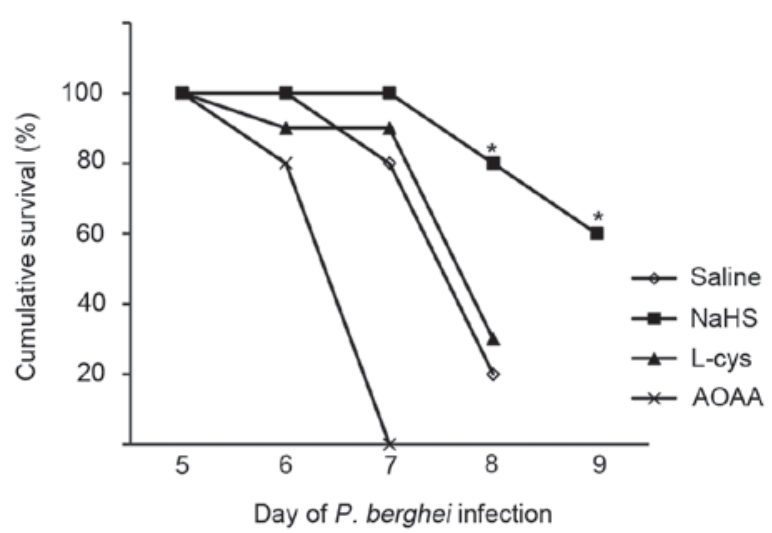

Figure 3. Cumulative survival of infected mice. Infected mice were treated with saline, $1 \mathrm{mg} / \mathrm{kg} \mathrm{NaHS}, 0.3 \mathrm{mg} / \mathrm{kg}$ L-cys or $10 \mathrm{mg} / \mathrm{kg}$ AOAA. L-cys, L-cysteine; AOAA, aminooxyacetic acid.

measured by ELISA (Fig. 5A). Compared with saline-treated group, MMP-9 protein levels in the NaHS-treated group $(28.48 \pm 0.87 \mathrm{ng} / \mathrm{ml})$ were significantly decreased $(\mathrm{P}<0.05$; Fig. 5A).

Inflammation of ECM. ELISA was used to evaluate the concentration of inflammatory factors in the plasma during ECM. On day 6, the levels of the proinflammatory cytokine IL-18 (Fig. 5B) and the inflammatory marker sCD40 (Fig. 5C) were significantly increased in the plasma of saline-treated mice compared with uninfected mice, and administration of the $\mathrm{H}_{2} \mathrm{~S}$ donor significantly reduced the concentration of IL-18 and sCD40 compared with saline-treated mice $(\mathrm{P}<0.05$; Figs. 5B and $\mathrm{C})$.

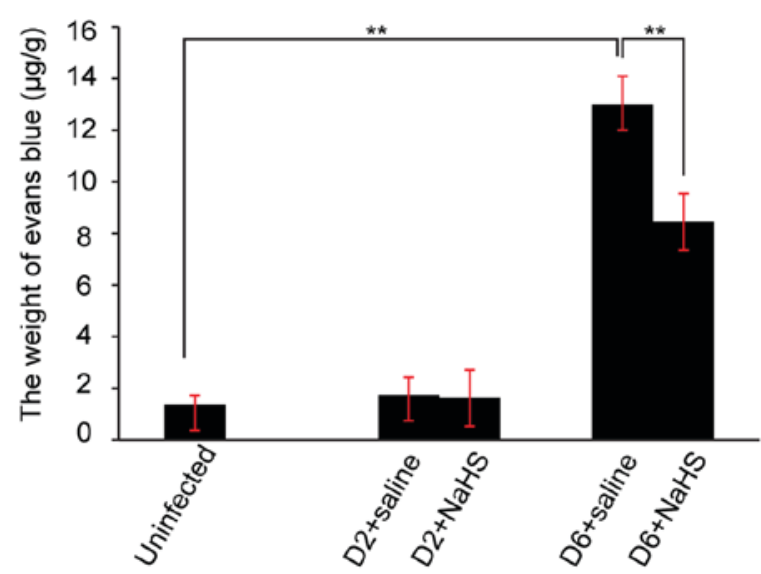

Figure 4. The weight of Evans blue in the brain was used as a measurement of the integrity of the blood brain barrier. Data are presented as the mean \pm standard error of the mean, $n=10$. ${ }^{* *} \mathrm{P}<0.01$ vs. uninfected group. D2+saline, infected group treated with saline for 2 days; D2+NaHS, infected group treated with NaHS for 2 days; D6+saline, infected group treated with saline for 6 days; D6+NaHS, infected group treated with NaHS for 6 days.

\section{Discussion}

The present study used a $P b A$-infected C57BL/6 mouse model to examine human cerebral malaria (13). Similar to the classical symptoms of humans with cerebral malaria, the infected C57BL/6 mice also manifest parasitemia, inflammation and vascular leak (16). Collectively, the findings of the present study demonstrated that mice infected with $P b A$ had pathophysiological markers of ECM. Sequential increased amounts of parasitized red blood cells indicated that successful invasion and proliferation of malaria parasite occurred in the C57BL/6 mice. Significant hemorrhaging into the brain was observed by H\&E staining on day 6 of ECM, suggesting that invasion and proliferation of the malaria parasite resulted in disruption of the BBB. In addition, the increased levels of inflammatory factors (IL-18 and sCD40) indicated that inflammation occurred following infection. Increased indexes of the spleen, brain and liver were additionally observed in the infection group, demonstrating that hepatomegaly and encephaledema appeared in the infected mice. These impairments are also observed in humans infected with cerebral malaria, providing support for the fact that this ECM model accurately reflected the clinical pathophysiology of ECM.

$\mathrm{H}_{2} \mathrm{~S}$ has been demonstrated by DellaValle et al (17) to prevent $P$. falciparum growth and metabolism in vitro, and the presence of endogenous $\mathrm{H}_{2} \mathrm{~S}$ in the human and rat brain has been established (18). However, the involvement of $\mathrm{H}_{2} \mathrm{~S}$ in cerebral malaria pathogenesis remains to be clarified. In order to evaluate whether $\mathrm{H}_{2} \mathrm{~S}$ is involved in ECM development, $\mathrm{H}_{2} \mathrm{~S}$ concentration was tested by ELISA. Consistent with previous reports, the levels of $\mathrm{H}_{2} \mathrm{~S}$ derived from the brain gradually decreased with time. For instance, patients with coronary heart disease have significantly decreased plasma sulphide levels, from 50 to $25 \mu \mathrm{M}$ (19). It is possible to mimic the decrease of plasma sulphide levels in rodent models, whereby spontaneously hypertensive rats $(20 \mu \mathrm{M})$ have substantially lower plasma sulphide levels than normotensive control Wistar Kyoto 
$\mathbf{A}$
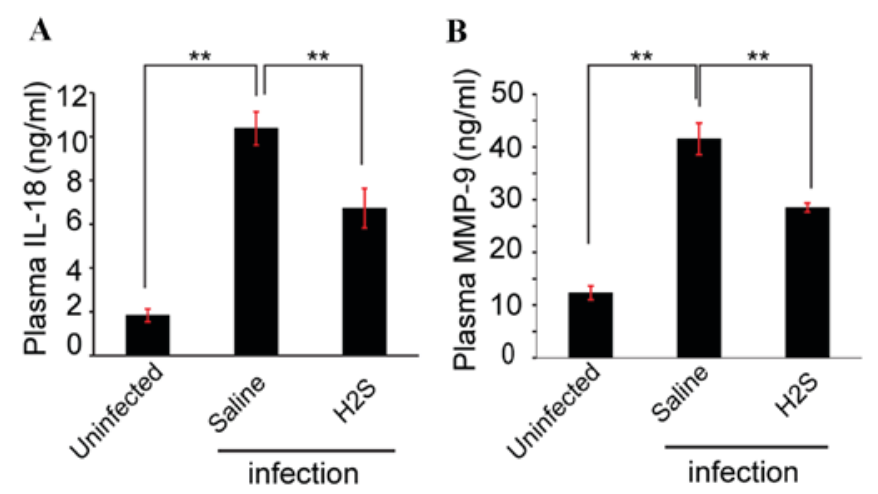

C

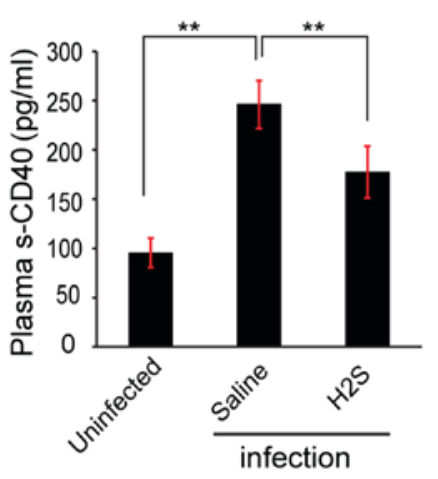

Figure 5. Plasma levels of (A) MMP-9 on day 6 after infection were used as an indicator of blood brain barrier integrity, and (B) IL-18 and (C) sCD40 were used as indicators of inflammation, as measured by ELISA. Data are presented as the mean \pm standard error of the mean, $n=10$. ${ }^{* *} \mathrm{P}<0.01$. MMP-9, matrix metalloproteinase-9; IL-18, interleukin-18; sCD40, serum cluster of differentiation 40 .

rats (48 $\mu \mathrm{M})$ (20). The present study reported that decreased $\mathrm{H}_{2} \mathrm{~S}$ in the brain may be involved in the development of ECM.

However, there are no data that explain how $\mathrm{H}_{2} \mathrm{~S}$ is decreased in the brain following infection with $\mathrm{PbA}$. It is well known that endogenous $\mathrm{H}_{2} \mathrm{~S}$ is generated from L-cysteine by three enzymes: CBS, cystathionine-synthase and 3-mercaptopyruvate sulfurtransferase. In the brain, the production of endogenous $\mathrm{H}_{2} \mathrm{~S}$ is initially attributed to the actions of CBS (21-23). RT-PCR and western blotting were used to determine CBS mRNA and protein levels, respectively. RT-PCR analysis indicated that the level of CBS mRNA in the brain progressively decreased following infection with $P b A$. This decrease in transcriptional regulation additionally manifested at the CBS protein level. Collectively, these results suggested that low $\mathrm{H}_{2} \mathrm{~S}$ bioavailability contributed to the development of ECM, that the primary reason for reduced $\mathrm{H}_{2} \mathrm{~S}$ concentrations during ECM may be inhibition of CBS transcription and translation caused by $P b A$ infection, and that the beginning of inhibition occurs three days following infection.

As low levels of $\mathrm{H}_{2} \mathrm{~S}$ in the brain contributes to the progression of ECM, it was hypothesized that administration of $\mathrm{H}_{2} \mathrm{~S}$ donors may provide protection against ECM. NaHS was used as an exogenous donor of $\mathrm{H}_{2} \mathrm{~S}$, L-cysteine was used as an endogenous donor of $\mathrm{H}_{2} \mathrm{~S}$ and AOAA was used as an inhibitor of CBS, which inhibits endogenous $\mathrm{H}_{2} \mathrm{~S}$ generation from L-cysteine. Quantitative assessment using a rapid murine coma and behavior scale was performed to evaluate the survival rate of ECM. The NaHS-treated groups demonstrated a longer survival time than the saline or L-cysteine-treated group, and the L-cysteine treated group had a similar survival time as the saline-treated group, indicating that the exogenous $\mathrm{H}_{2} \mathrm{~S}$ donor NaHS provided protection against $\mathrm{PbA}$-induced death, but the endogenous $\mathrm{H}_{2} \mathrm{~S}$ donor L-cysteine did not protect against $\mathrm{PbA}$ infection. These findings provided evidence to demonstrated that the ability of endogenous $\mathrm{H}_{2} \mathrm{~S}$ generation from L-cysteine is deficient during ECM, as confirmed by the decreased levels of CBS measured by RT-PCR and western blotting. Furthermore, the AOAA treated group had the same survival time as the saline-treated group and a shorter survival time than the NaHS-treated group, which further confirmed the involvement of $\mathrm{H}_{2} \mathrm{~S}$ in the development of ECM.

For two main reasons, the present study aimed to further investigate the effects of $\mathrm{H}_{2} \mathrm{~S}$ on inflammation. First, it is well known that $P$. falciparum erythrocyte membrane protein 1 is a parasite protein that is expressed on the infected erythrocyte surface and mediates parasite binding to receptors, including CD36 and intercellular adhesion molecule-1 (16,24-26). This leads to conglutination of infected erythrocytes on the brain micro-vascular endothelial cells and accompanying inflammation. Furthermore, the sequestration of parasitized erythrocytes within the brain blood vessels is worsened by pro-inflammatory responses (27). Activated T cell-mediated immune responses have been demonstrated to be involved in the generation of cerebral malaria (28-30). Secondly, $\mathrm{H}_{2} \mathrm{~S}$ decreases inflammation and leukocyte-endothelial cell interactions in vivo via inhibition of leukocyte rolling and adhesion, as well as ensuing diapedesis (8). The present study used ELISA to investigate whether administration of the $\mathrm{H}_{2} \mathrm{~S}$ donor decreased proinflammatory biomarkers during ECM. Compared with saline-treated mice, the observed decreases of IL-18 (a proinflammatory cytokine) and sCD40 (an inflammatory marker) in NaHS-treated mice on day 6 of ECM suggested that $\mathrm{H}_{2} \mathrm{~S}$ donor administration reduced inflammation of ECM.

Notably, the high mortality of ECM is mainly attributed to the sequestration of infected red blood cells in the endothelial cells, which further disrupts the integrity of the BBB (31-34), with flaws in the BBB being associated with the advance of cerebral disease $(34,35)$. Three methods were used by the present study to assess the integrity of the BBB during ECM: H\&E staining of brain tissue to test cerebrovascular hemorrhage, extravasation of Evans blue in the brain to test cerebrovascular permeability, and levels of MMP-9 in the plasma, which is a protease that contributes to the disruption of endothelial barrier integrity (36). Compared with the saline-treated group, decreased extravasation of Evans blue, and reduced and hemorrhage and MMP-9 levels, were observed in the NaHS administration group, indicating that NaHS protected against disruption of the BBB induced by $\mathrm{PbA}$ infection. The underlying mechanisms by which $\mathrm{H}_{2} \mathrm{~S}$ protected against disruption of the BBB merit further investigation.

In conclusion, the present study demonstrated that low levels of brain $\mathrm{H}_{2} \mathrm{~S}$ contributes to the progression of ECM. Furthermore, administration of an exogenous $\mathrm{H}_{2} \mathrm{~S}$ donor protected against disruption of the BBB induced by $\mathrm{PbA}$ infection, and decreased proinflammatory biomarkers in the brain. Therefore, exogenous $\mathrm{H}_{2} \mathrm{~S}$ may be a useful complementary therapy for the treatment of ECM. 


\section{References}

1. Mung'Ala-Odera V, Snow RW and Newton CR: The burden of the neurocognitive impairment associated with Plasmodium falciparum malaria in sub-saharan Africa. Am J Trop Med Hyg 71 (2 Suppl): S64-S70, 2004.

2. van Hensbroek MB, Palmer A, Jaffar S, Schneider G and Kwiatkowski D: Residual neurologic sequelae after childhood cerebral malaria. J Pediatr 131: 125-129, 1997.

3. Wallace JL, Blackler RW, Chan MV, Da Silva GJ, Elsheikh W, Flannigan KL, Gamaniek I, Manko A, Wang L, Motta JP and Buret AG: Anti-inflammatory and cytoprotective actions of hydrogen sulfide: Translation to therapeutics. Antioxid Redox Signal 22: 398-410, 2015

4. Wallace JL, Caliendo G, Santagada V, Cirino G and Fiorucci S: Gastrointestinal safety and anti-inflammatory effects of a hydrogen sulfide-releasing diclofenac derivative in the rat. Gastroenterology 132: 261-271, 2007.

5. Yang C, Yang Z, Zhang M, Dong Q, Wang X, Lan A, Zeng F, Chen P, Wang $\mathrm{C}$ and Feng J: Hydrogen sulfide protects against chemical hypoxia-induced cytotoxicity and inflammation in $\mathrm{HaCaT}$ cells through inhibition of ROS/NF- $\mathrm{kB} / \mathrm{COX}-2$ pathway. PLoS One 6: e21971, 2011.

6. Li L, Rossoni G, Sparatore A, Lee LC, Del Soldato P and Moore PK: Anti-inflammatory and gastrointestinal effects of a novel diclofenac derivative. Free Radic Biol Med 42: 706-719, 2007.

7. Wallace JL: Hydrogen sulfide-releasing anti-inflammatory drugs. Trends Pharmacol Sci 28: 501-505, 2007.

8. Zanardo RC, Brancaleone V, Distrutti E, Fiorucci S, Cirino G and Wallace JL: Hydrogen sulfide is an endogenous modulator of leukocyte-mediated inflammation. FASEB J 20: 2118-2120, 2006.

9. Kimura H: Hydrogen sulfide induces cyclic AMP and modulates the NMDA receptor. Biochem Biophys Res Commun 267: 129-133, 2000.

10. Kimura H: Hydrogen sulfide as a neuromodulator. Mol Neurobiol 26: 13-19, 2002.

11. Whiteman M, Cheung NS, Zhu YZ, Chu SH, Siau JL, Wong BS, Armstrong JS and Moore PK: Hydrogen sulphide: A novel inhibitor of hypochlorous acid-mediated oxidative damage in the brain? Biochem Biophys Res Commun 326: 794-798, 2005.

12. Whiteman M, Li L, Rose P, Tan CH, Parkinson DB and Moore PK: The effect of hydrogen sulfide donors on lipopolysaccharide-induced formation of inflammatory mediators in macrophages. Antioxid Redox Signal 12: 1147-1154, 2010.

13. de Oca MM, Engwerda $\mathrm{C}$ and Haque A: Plasmodium berghei ANKA (PbA) infection of C57BL/6J mice: A model of severe malaria. Methods Mol Biol 1031: 203-213, 2013.

14. Carroll RW, Wainwright MS, Kim KY, Kidambi T, Gómez ND, Taylor T and Haldar K: A rapid murine coma and behavior scale for quantitative assessment of murine cerebral malaria. PLoS One 5: pii: e13124, 2010.

15. Baccarella A, Huang BW, Fontana MF and Kim CC: Loss of Toll-like receptor 7 alters cytokine production and protects against experimental cerebral malaria. Malar J 13: 354, 2014

16. Chang WL, Jones SP, Lefer DJ, Welbourne T, Sun G, Yin L, Suzuki H, Huang J, Granger DN and van der Heyde HC: CD8(+)-T-cell depletion ameliorates circulatory shock in Plasmodium berghei-infected mice. Infect Immun 69: 7341-7348, 2001.

17. DellaValle B, Staalsoe T, Kurtzhals JA and Hempel C: Investigation of hydrogen sulfide gas as a treatment against $\mathrm{P}$. falciparum, murine cerebral malaria, and the importance of thiolation state in the development of cerebral malaria. PLoS One 8 e59271, 2013.

18. Goodwin LR, Francom D, Dieken FP, Taylor JD, Warenycia MW, Reiffenstein RJ and Dowling G: Determination of sulfide in brain tissue by gas dialysis/ion chromatography: Postmortem studies and two case reports. J Anal Toxicol 13: 105-109, 1989.
19. Jiang HL, Wu HC, Li ZL, Geng B and Tang CS: Changes of the new gaseous transmitter $\mathrm{H} 2 \mathrm{~S}$ in patients with coronary heart disease. Di Yi Jun Yi Da Xue Xue Bao 25: 951-954, 2005 (In Chinese).

20. Du J, Yan H and Tang C: Endogenous H2S is involved in the development of spontaneous hypertension. Beijing Da Xue Xue Bao 35: 102, 2003 (In Chinese).

21. Porter PN, Grishaver MS and Jones OW: Characterization of human cystathionine beta-synthase. Evidence for the identity of human L-serine dehydratase and cystathionine beta-synthase. Biochim Biophys Acta 364: 128-139, 1974.

22. Ichinohe A, Kanaumi T, Takashima S, Enokido Y, Nagai Y and Kimura $\mathrm{H}$ : Cystathionine beta-synthase is enriched in the brains of Down's patients. Biochem Biophys Res Commun 338: 1547-1550, 2005.

23. Enokido Y, Suzuki E, Iwasawa K, Namekata K, Okazawa H and Kimura H: Cystathionine beta-synthase, a key enzyme for homocysteine metabolism, is preferentially expressed in the radial glia/astrocyte lineage of developing mouse CNS. FASEB J 19: 1854-1856, 2005 .

24. van der Heyde HC, Nolan J, Combes V, Gramaglia I and Grau GE: A unified hypothesis for the genesis of cerebral malaria: Sequestration, inflammation and hemostasis leading to microcirculatory dysfunction. Trends Parasitol 22: 503-508, 2006.

25. Razakandrainibe R, Pelleau S, Grau GE and Jambou R: Antigen presentation by endothelial cells: What role in the pathophysiology of malaria? Trends Parasitol 28: 151-160, 2012.

26. Franke-Fayard B, Janse CJ, Cunha-Rodrigues M, Ramesar J, Büscher P, Que I, Löwik C, Voshol PJ, den Boer MA, van Duinen SG, et al: Murine malaria parasite sequestration: $\mathrm{CD} 36$ is the major receptor, but cerebral pathology is unlinked to sequestration. Proc Natl Acad Sci USA 102: 11468-11473, 2005.

27. Nie CQ, Bernard NJ, Schofield L and Hansen DS: CD4+ CD25+ regulatory $\mathrm{T}$ cells suppress $\mathrm{CD} 4+\mathrm{T}$-cell function and inhibit the development of Plasmodium berghei-specific TH1 responses involved in cerebral malaria pathogenesis. Infect Immun 75: 2275-2282, 2007.

28. Hearn J, Rayment N, Landon DN, Katz DR and de Souza JB: Immunopathology of cerebral malaria: Morphological evidence of parasite sequestration in murine brain microvasculature. Infect Immun 68: 5364-5376, 2000.

29. Nitcheu J, Bonduelle O, Combadiere C, Tefit M, Seilhean D, Mazier D and Combadiere B: Perforin-dependent brain-infiltrating cytotoxic CD8+ T lymphocytes mediate experimental cerebral malaria pathogenesis. J Immunol 170: 2221-2228, 2003.

30. Pais TF and Chatterjee S: Brain macrophage activation in murine cerebral malaria precedes accumulation of leukocytes and CD8+ T cell proliferation. J Neuroimmunol 163: 73-83, 2005.

31. Miller LH, Ackerman HC, Su XZ and Wellems TE: Malaria biology and disease pathogenesis: Insights for new treatments. Nat Med 19: 156-167, 2013.

32. Wautier JL and Wautier MP: Molecular basis of erythrocyte adhesion to endothelial cells in diseases. Clin Hemorheol Microcirc 53: 11-21, 2013.

33. Combes V, El-Assaad F, Faille D, Jambou R, Hunt NH and Grau GE: Microvesiculation and cell interactions at the brain-endothelial interface in cerebral malaria pathogenesis. Prog Neurobiol 91: 140-151, 2010.

34. Medana IM and Turner GD: Human cerebral malaria and the blood-brain barrier. Int J Parasitol 36: 555-568, 2006.

35. Brown H, Hien TT, Day N, Mai NT, Chuong LV, Chau TT, Loc PP, Phu NH, Bethell D, Farrar J, et al: Evidence of blood-brain barrier dysfunction in human cerebral malaria. Neuropathol Appl Neurobiol 25: 331-340, 1999.

36. Zheng M, Wei J, Tang Y, Yang C, Wei Y, Yin X and Liu Q: ApoE-deficient promotes blood-brain barrier disruption in experimental autoimmune encephalomyelitis via alteration of MMP-9. J Mol Neurosci 54: 282-290, 2014. 